\title{
XIV
}

\section{A LUTA ANTIMANICOMIAL EM TEMPOS DE PANDEMIA: A PERMANENTE PAUTA PARA O SERVIÇO SOCIAL BRASILEIRO*}

\author{
Fabiola Xavier Leal \\ Maria Lúcia Teixeira Garcia \\ Mirian Cátia Vieira Basílio Denadai
}

\section{Introdução}

Este capítulo tem como objetivo refletir sobre a atuação do movimento da luta antimanicomial com foco no estado do Espírito Santo em tempos de pandemia, a fim de identificar as ações empreendidas para o enfrentamento das demandas na área. $E$, a partir disso, reafirmar que essa luta é também uma luta do Serviço Social brasileiro, devendo ser fortalecida pela categoria profissional nos seus espaços de atuação e nos movimentos oficialmente constituídos em suas regiões. Importante dizer que contextualizamos esse debate a partir da perspectiva teórica gramsciana, compreendendo que as categorias analíticas apresentadas por esse autor elucidam o debate sobre Movimentos sociais e suas configurações no campo da sociedade civil na sociedade capitalista.

É preciso reforçar que as lutas políticas não se dão apenas no âmbito da sociedade civil, mas na totalidade da estrutura social e da formação social constituindo o bloco histórico. E a sociedade civil deve ser tratada a partir de um viés político que articule a sua relação com a base econômica, constituindo-se em um espaço heterogêneo e com contradições de classe. Nessa perspectiva, o conceito de sociedade civil em Gramsci subsidia o debate sobre as práticas sociais e políticas em torno do controle social ${ }^{1}$ (BRAVO; CORREIA, 2012), sendo um pouco essa dimensão que pretendemos abordar aqui, consi-

*DOI- 10.29388/978-65-86678-44-4-0-f.361-386 
derando que o Movimento como_o da luta antimanicomial se insere nesse contexto. As reflexões gramscianas possibilitam apreender a processualidade e a historicidade do social, e também o jogo das relações que vão permitir desvendar a realidade e suas contradições (SIMIONATTO, 1998).

Partindo dessas premissas, entendemos que o debate sobre a luta antimanicomial e a política de saúde mental e seus processos antagônicos está intimamente relacionado a uma sociedade, numa tentativa de envolver diferentes sujeitos sociais em torno de uma determinada valoração ética, vinculada a determinados projetos societários presentes na sociedade capitalista (LEAL, 2006).

Nessa perspectiva, no âmbito da saúde destacamos aqui o principal Movimento que empreendeu as lutas políticas nesse campo a partir da década de 1970, que foi o pela Reforma Sanitária no Brasil. Esse movimento defendeu a necessidade da participação social no conjunto das lutas contra a privatização da saúde e a sua regulação pelo mercado, colocando em discussão a tendência hegemônica de prestação de assistência médica como fonte de lucro (PAIM, 1997). Como um Movimento, se consolidou com a realização da 8a Conferência de Saúde (1986), na qual se efetivou a participação da sociedade civil nas deliberações, as garantias constitucionais na Constituição Federal de 1988 (CF/88) e também a criação do Sistema Único de Saúde (SUS) na década seguinte (BRAVO; CORREIA, 2012). Pari passu a essa organização, configurou-se e avançou também o Movimento pela Reforma Psiquiátrica brasileira, com as lutas empreendidas pelo Movimento chamado antimanicomial. A mobilização intensa de lutas da sociedade em defesa dos direitos sociais no fim da década de 1970 e na década seguinte foram travadas em um contexto da abertura do regime militar, levando à promulgação da CF que incorporou novos valores e critérios ao sistema de proteção social brasileiro (RAI-

\footnotetext{
${ }^{1}$ Entendendo, na concepção gramsciana, o controle social a partir da relação Estado/sociedade civil, em que o controle não é de um ou do outro, mas sim das classes sociais, podendo acontecer via políticas públicas. Na perspectiva das classes subalternas, o controle social tem na atuação de setores organizados na sociedade civil que as representam a possibilidade do controle da gestão das políticas públicas para que atendam, cada vez mais, às demandas e aos interesses dessas classes. Será, portanto, a capacidade das classes subalternas em luta que vai definir o tamanho da interferência na gestão pública, orientando as ações do Estado, visando sempre a construção de sua hegemonia (CORREA, 2007).
} 
CHELIS, 2005). E é também nessa conjuntura, que as experiências empreendidas pelo Movimento no campo antimanicomial devem ser postas vis a vis com o momento histórico marcado por um processo de redemocratização, com alguns avanços políticos e sociais significativos.

Esse Movimento pela Reforma Psiquiátrica (MRP) é uma denominação mais genérica acerca de um processo que envolve diferentes segmentos na luta em defesa da melhoria das condições dos sujeitos em sofrimento psíquico. Compõem esse Movimento diferentes sujeitos políticos que organizam o Movimento da Luta Antimanicomial (MLA). O MRP também envolve corporações da área, universidades, setores contra hegemônicos do governo, entre outros sujeitos de forma a se constituir em um movimento amplo (PITTA, 2011) e com articulações mais institucionais, com espaço político maior no Estado (VASCONCELOS, 2010).

Portanto, como qualquer movimento social, o MRP deve ser compreendido em um campo de muitas disputas e contradições. Para que ocorra um processo de implementação de uma reforma no campo psiquiátrico, Amarante (1995) diz que quatro dimensões são necessárias: a técnico-conceitual, a técnico-assistencial, a jurídico político e a dimensão sociocultural (AMARANTE, 1995). Vasconcelos (2020) também chama a atenção que para alcançarmos uma sociedade sem manicômios é necessário condicionar essa mudança a um projeto societário mais amplo que seja economicamente e politicamente democrático. E que esse projeto há muito tempo se encontra em profunda crise e ameaça.

As propostas da RP não se limitou à reforma de serviços e aspectos terapêuticos com outras tecnologias de cuidado, mas também apresentou estratégias e dispositivos políticos, sociais e culturais (AMARANTE; NUNES, 2018). A desinstitucionalização passa a ser um dos principais princípios norteadores da RP, a partir de um conjunto de iniciativas que objetivam transformar o aparato manicomial e, com isso possibilitar mudanças mais radicais no trato da sociedade com a loucura (ALMEIDA FILHO et al., 2015), permanecendo a bandeira de luta após a implementação da Lei no 10.216 em 2001 (DUAR$T E$, 2014). A saúde mental, assim, exigiu o seu ingresso no campo da saúde coletiva, de modo que a política e o social deixaram de ser ad- 
jetivos para se tornarem substantivas na construção de um pensamento social da saúde (CAVALCANTE, 2020).

A consolidação da Reforma ainda vem se dando, ora a passos mais largos, ora lentamente, podendo ser vista pelo aparato normativo legal ao longo dos anos, além das outras dimensões (DENADAl, 2015). Os pressupostos da RP demarcaram alguns paradigmas importantes em conjunto com a Reforma Sanitária, pois trouxeram melhorias significativas para um novo modelo de Atenção em Saúde Pública, atingindo diversas instituições e suas práticas de modo a inscrever novas formas de promover e produzir saúde (AMARANTE, 2007; MERHY; AMARAL, 2007).

Então, cabe buscarmos compreender como a luta antimanicomial contribui e vem contribuindo para a ampliação das políticas sociais em saúde e em saúde mental. E nessa esteira, como essa pressiona o Estado, como se articula com outros sujeitos políticos e ainda, como se insere no movimento de totalidade das lutas de forma a buscar construir mudanças radicais que poderão alterar a realidade. Advertimos, portanto, que essa compreensão demanda de todos os envolvidos um aprofundamento no conhecimento sobre essa trajetória, sobre os sujeitos que historicamente estiveram envolvidos, assim como um balanço do que se conquistou a partir da incidência do Movimento. Aqui, nosso objetivo não alcança essa análise, mas visa apontar algumas reflexões dos tempos atuais, considerando ainda o contexto desafiador de uma pandemia por COVID-19.

Um primeiro aspecto é compreender as concepções a respeito do que é o MLA². Para Soalheiro (2003), é um conjunto de estraté-

\footnotetext{
${ }^{2}$ O Movimento pela reforma tem início com uma série de denúncias das violências como tortura, fraudes e corrupção cometidas nas instituições psiquiátricas. Desde então, organiza-se o Movimento dos Trabalhadores em Saúde Mental (MTSM), a partir do Centro Brasileiro de Estudos de Saúde (CEBES) (criado em 1976) e do Movimento de Renovação Médica (REME), que eram espaços de discussão e produção do pensamento crítico. As reivindicações eram por aumento salarial, redução do número excessivo de consultas por turno de trabalho, posição contrária ao manicômio e ao eletrochoque, humanização dos serviços, assim como meIhorias na assistência prestada à população. Os/as trabalhadores/as fizeram uma greve em 1978 que durou oito meses, tendo muita repercussão midiática. Em 1987, esse movimento passou a denominar-se Movimento de Luta Antimanicomial e caminhou com uma pauta de mobilizações contra o modelo asilar. Reuniu trabalhadores, intelectuais, pessoas com transtorno mental e seus familiares. Estabeleceu intercâmbios com outros movimentos no exterior (AMARANTE; NUNES, 2018).
} 
gias políticas, jurídicas, culturais que criam, possibilitam e marcam a presença da loucura na cidade. Para Lobosque (2001), é uma instância política inscrita num processo mais amplo de transformações sociais, cujo objetivo central é o combate às formas de exclusão que tomam a loucura como objeto, o que seria radical, a medida que as formas de exclusão da loucura resumem formas muito poderosas de exclusão operantes em nossa cultura. O Manifesto de Bauru (1987), considerado o documento de fundação do MLA declarou a importância da articulação entre profissionais e a sociedade para o enfrentamento da questão da loucura e suas formas de tratamento ( $\mathrm{LÜCH}$ MANN; RODRIGUES, 2007), numa perspectiva de romper radicalmente com as abordagens tecnicistas adotadas até então (LOBOSQUE, 2001).

O Movimento, então, passa a incorporar outros sujeitos na luta pela transformação das políticas e práticas psiquiátricas (AMARANTE, 1995) ${ }^{3}$. Gestam-se várias articulações de forma a constituir diversos núcleos do movimento até que em 1993 o Movimento Nacional da Luta Antimanicomial (MNLA) se consolida no I Encontro Nacional da Luta Antimanicomial em Salvador/BA como um movimento social, plural, independente, autônomo e devendo manter parcerias com outros movimentos sociais. Para isso, o fortalecimento se daria a partir de novos espaços de reflexões para que a sociedade também se apropriasse da luta (VASCONCELOS, 2002).

Com essa organização, os sujeitos políticos que vinham construindo a RP nessas décadas se articulam de tal forma que em 2000 assumiu a Coordenação Nacional de Saúde Mental, álcool e outras drogas do Ministério da Saúde um médico militante da luta antimanicomial - Pedro Gabriel Delgado (irmão do propositor da Lei da Saúde Mental), ficando nesse cargo por 10 anos. Entretanto, mesmo com várias conquistas nesse período, como é um jogo de forças, há também fortes embates de posicionamentos políticos e de saber. Houve uma crise e uma cisão no movimento na década de 2000 - MNLA e a Rede Nacional Internúcleos da Luta Antimanicomial (RENILA), cuja divisão dificultou ainda mais as articulações das propostas e das inicia-

\footnotetext{
${ }^{3}$ Na década de 1990, também surgem algumas organizações na área da redução de danos Como a Associação Brasileira de Redução de Danos (ABORDA) e a Rede Brasileira de Redução de Danos e Direitos Humanos (REDUC).
} 
tivas comuns devido às tendências divergentes, o que se mantem até hoje.

É, portanto, a correta análise das relações de força contidas nesse contexto de disputas e organização de um determinando Movimento que vai nos permitir compreender que os fenômenos parciais da vida política e social desse movimento, ao serem remetidos à totalidade, podem sugerir estratégias e táticas, seja para manter a ordem vigente, seja para fortalecer a construção de uma nova hegemonia (SIMIONATTO, 1998), que no caso aqui se localiza no campo da saúde mental brasileira.

Se consideramos que o contexto anterior já era desafiador, repleto de contradições e limitações para os diversos movimentos sociais com o recrudescimento das instâncias de controle social, ainda somos confrontados com o avanço de ações de expansão dos interesses manicomiais, desmonte da saúde e, recentemente, a emergência de uma pandemia no início da segunda década dos anos 2000. O que tem exigido uma reorganização de toda a vida e, consequentemente dessas militâncias e das maneiras de constituir e organizar os enfrentamentos em nome das consolidadas bandeiras de luta. Fazer uma análise correta é condição sine qua non para pensarmos a ação. Para tanto, é importante dizer que nos últimos anos, desde o Governo Dilma, seguido pelo Governo Temer e atualmente com o Governo Bolsonaro, presenciamos muitos ataques e retrocessos nas políticas de saúde mental e sobre drogas brasileiras. Sendo o subfinanciamento, o problema mais robusto de toda a reforma psiquiátrica brasileira (ALMEIDA, 2019).

A partir de 2017 temos um SUS que passou da condição de subfinanciado à de desfinanciado, com a Emenda Constitucional (EC) n. 95 dos Gastos Públicos ${ }^{4}$. Medida essa que integra um conjunto de contrarreformas $^{5}$ neoliberais do Estado brasileiro como a Reforma Trabalhista e a Reforma da Previdência ${ }^{6}$, em uma conjuntura de crise

\footnotetext{
${ }^{4}$ A EC 95 apresenta um teto fixo de gastos por 20 anos, a partir de 2017 nas políticas de educação, saúde e assistência social.

${ }^{5}$ Nos dizeres de Behring (2003), a expressão "reforma" do Estado tem um sentido totalmente ideológico. Tratar-se-ia, ao contrário de uma "contrarreforma" do Estado pois tudo muda para permanecer como está.

${ }^{6} \mathrm{~A}$ reforma previdenciária representa a articulação entre setores conservadores e agências financeiras internacionais para privatizar o sistema previdenciário através da redução da pre-
} 
e mundialização do capital onde a financeirização e as medidas neoliberais têm se apresentado como a principal política no processo de redefinição da taxa de lucratividade, estagnada desde a segunda metade da década de 1970 (VASCONCELOS, 2020). Essas profundas mudanças alinhadas com os interesses que servem ao capital internacional e ao empresariado produzem um redirecionamento das políticas sociais, com sérios impactos para o conjunto da classe trabalhadora. Essas contrarreformas são um conjunto de alterações regressivas nos direitos do mundo do trabalho e em geral, alteram os marcos legais, os quais já não expressam as demandas da classe trabalhadora, mas que foram conquistados pela luta de classe (GRANEMANN, 2004).

Portanto, reconhecer o substrato neoliberal pode contribuir no fortalecimento do vetor político no cotidiano de trabalho e nos articular com resistências e lutas com outros movimentos como o sindical, antiproibicionista no campo das drogas, estudantil, feministas, antirracistas e tantos outros com características emancipatórias. Importante dizer que "a reforma psiquiátrica brasileira não é mais infante e está tendo a oportunidade de reavaliar os pressupostos tomados de empréstimo das teorias social e política para uma autocrítica radical aos componentes epistemológico, cultural, legal e assistencial" (CAVALCANTE, 2020, p. 42).

Vasconcelos $(2012 ;$ 2016) já alertava, desde o início da década passada, aos profissionais, gestores de políticas e ativistas antimanicomiais sobre essa conjuntura de crises, no sentido de estarem atentos às profundas consequências e novas demandas que as transformações econômicas, sociais e ambientais emergem e impactam nas lutas de resistência da classe trabalhadora. Embora tivéssemos avanços edificados ao longo dos anos 1990 a 2010 na saúde mental, o neoliberalismo condiciona a RP brasileira nas últimas três décadas e meia a um declínio (LIMA, 2019). Somado a isso temos uma atualização neoconservadora do componente de contrarreforma da nossa democracia (CAVALCANTE, 2020). O conservadorismo ${ }^{7}$ encontra-se

vidência pública e supervalorização da previdência complementar. O que fere frontalmente os princípios da Carta Constitucional de 1988 sobre seguridade social (saúde, previdência e assistência social). Não só não a fortalece como desintegra a unificação das três políticas públicas que a compõe.

${ }^{7}$ A noção corrente do pensamento conservador está ligada ao verbo conservar. A partir da noção, segundo a qual, sempre queremos preservar aquelas coisas e aquelas ideias que valo- 
em uma fase de reatualização ampliada nas diversas esferas da vida social (NETTO, 2011), com o fundamentalismo religioso que repercute no plano político de forma intolerante ao que é diferente e divergente (PINHEIRO, 2015).

Deve estar contido nisso também, e não menos importante, o fio condutor sobre os determinantes relacionados à formação sóciohistórica brasileira. Formação essa, na qual, o desenvolvimento do capitalismo se gesta sem uma oposição às expressões do atraso e às velhas práticas coloniais, mas que ao mesmo tempo absorve o passado de forma funcional, com um processo de socialização da política inconcluso, sendo as massas populares neutralizadas por um Estado que atuou historicamente como vetor de desestruturação da sociedade civil, de forma a coibir a emersão de projetos democráticos alternativos, impactando assim as organizações das classes trabalhadoras (LEAL, 2017). A violência do Estado pelos órgãos de repressão se inscreve numa tradição multissecular de controle dos miseráveis pela força a partir de uma tradição que vem desde a escravidão, passa pelos conflitos agrários e se aprofunda na ditadura militar. Essa articulação orgânica de repressão às classes consideradas "perigosas" e assistencialização das políticas sociais constituem uma expressiva face contemporânea da barbárie, em umas das suas múltiplas faces, articulando violência permanente e assistencialismo minimalista (NETTO, 2012).

Tudo isso vai imprimir uma nova dinâmica ao conjunto das relações sociais (NETTO; BRAZ, 2007) na qual a apreensão fragmentada da realidade e a reificação que invade todas as esferas da vida social (NETTO, 1981) favorece a análise superficial de modo aparente. O que contribui para ocultar a essência dos processos e gerar a impressão de que os fenômenos são naturais e absolutos. A ideologia neoliberal e seu subproduto - a ideologia pós-moderna (HARVEY, 2008) servem ainda mais para sedimentar essa naturalização.

Portanto, o desafio para o campo da resistência não se modifica com o advento dos desafios da crise sanitária atual, no sentido de

rizamos e em que acreditamos. Assim, vale alertar que esta ideia é "lastreada no senso comum, não permite fundar qualquer reflexão que vá além dos limites do pensamento cotidiano, uma vez que, com sua ilimitada abrangência, não tem nenhuma possibilidade explicativa" (NETTO, 2011, p. 36). 
demandar de toda a militância uma atitude teórica realmente dialética desde sempre. Quanto mais se conhece os processos em que está inserido, mais livre é o sujeito para circunscrever os fins que visa (LEAL, 2020). Vasconcelos, em seus alertas (2020), fez a crítica de que a esquerda brasileira formada nas lutas sociais e políticas das décadas de 1970 a 2000 está despreparada e desorientada. E, consequentemente isso impacta diretamente o campo da saúde mental que foi e ainda é constituído principalmente por militantes da esquerda brasileira. No cenário atual, alerta Löwy (2020), ainda temos o enfrentamento do campo da esquerda e das forças populares brasileiras contra o neofascismo. Esse enfrentamento ainda está no início, o que demandará ainda mais do que simples protestos de bater panelas pelas janelas para derrotar o que está colocado.

Essa conjuntura de crise de hegemonia das esquerdas e dos projetos socialistas de modo geral abrem brechas para a reatualização do conservadorismo e, com isso, um forte apoio aos mitos, incitando atitudes autoritárias e discriminatórias, comportamentos e ideias valorizadoras da hierarquia, das normas institucionalizadas, da moral tradicional, da ordem e da autoridade (BARROCO, 2011). Temos uma espetacular ascensão no mundo inteiro, de governos de extrema direita, em alguns casos com traços neofascistas. Um dos maiores exemplos disso é o caso brasileiro com a eleição de uma figura (Jair Bolsonaro) que vem capitaneando muitos adeptos às suas bandeiras reacionárias com discursos e atos homofóbicos, racistas, fascistas e misóginos.

Mas, Löwy (2020) chama a atenção para o fato de que enquanto o fascismo clássico defendia a intervenção massiva do Estado na economia, o neofascismo como o de Bolsonaro é totalmente identificado com o neoliberalismo, de forma que impõe políticas sociais e econômicas favoráveis à oligarquia. E nesse contexto pandêmico, a crise sanitária tem tido consequências muito mais trágicas do que em outros países, principalmente para as camadas mais pobres da população. Outra característica peculiar, para Löwy, do neofascismo brasileiro é que, apesar da retórica ultranacionalista e patriótica, é altamente subordinado ao imperialismo norte-americano do ponto de vista econômico, diplomático, político e militar. A sua condução no enfrentamento da pandemia é catastrófica. Tentou impor, contra al- 
guns governos estaduais e seus próprios ministros da saúde, uma política que recusa as medidas sanitárias mínimas necessárias (apontadas pelo próprio governo - Ministério da Saúde e as agências reguladoras como a Agência Nacional de Vigilância Sanitária - ANVISA). Essas atitudes apresentam traços típicos do fascismo, como o darwinismo social que reforça a sobrevivência dos mais fortes e aptos.

Tudo isso ocorrendo em um contexto anterior de crise econômica e de retrocessos na saúde, conforme mencionado, que anteciparam um cenário no qual os que chegarem aos hospitais, poderão não encontrar atendimento mesmo se contaminados gravemente pelo coronavírus. E os que demandam outras intervenções em saúde também terão que esperar, não somente pela necessidade do distanciamento e da prioridade na pandemia, mas também pelo sucateamento ainda maior do que existia antes.

Para Antunes (2020), há uma interconexão profunda entre essa crise econômica instalada e a crise do coronavírus, as quais vêm impactando profundamente a classe trabalhadora. Temos presenciado a ampliação do empobrecimento e dos níveis de miséria em amplas parcelas e segmentos dessa classe, cujo cotidiano já era pautado por uma exploração do trabalho intensa ou pela precarização, desemprego, subemprego e informalidade, fenômenos explosivos em uma dimensão global. Quanto aos que estavam trabalhando antes da pandemia, também estavam crescentemente sob a modalidade da uberização sem a garantia de direitos. Em meio a essa profunda crise estrutural do capital, esse quadro vem se acentuando exponencialmente com a eclosão do coronavírus. Se não tínhamos uma retaguarda social com a devastação e a corrosão dos direitos intensificados particularmente de 2016 para cá, o cenário no país agora é de alquimia empresarial ainda mais letal na era da pandemia, nas palavras de Antunes (2020). A atitude de Bolsonaro é "áspera: se voltarem ou permanecerem em seus postos de trabalho, se convertem em reais candidatos à vala comum dos cemitérios. Se acatarem o isolamento e a quarentena, morrerão de fome" (ANTUNES, 2020, p. 183).

É, nesse cenário enormemente desafiador que passamos a discorrer sobre as ações empreendidas pelo Movimento antimanicomial no ES nesses tempos, buscando relacionar essa conjuntura retra- 
tada aqui com os desafios postos para as lutas e para os profissionais de Serviço Social

Assim, o capítulo está dividido em 2 sessões, sendo a primeira uma breve reflexão sobre a luta antimanicomial no ES no contexto da pandemia e no segundo momento, uma retomada dessa pauta como uma demanda permanente para o Serviço Social brasileiro. Nas considerações finais, retomamos Gramsci com seu otimismo mais do que nunca necessário no campo da vontade para permanecermos nas lutas, as quais serão travadas por longuíssimo tempo.

\section{A luta antimanicomial capixaba em tempos de pandemia: de casa, nas ruas e na luta resistindo e propondo}

O Movimento Antimanicomial no estado do Espírito Santo existe tradicionalmente desde a década de 1980 com as bandeiras constituídas historicamente pelo MNLA. Entre idas e vindas na sua organização, composição e articulações ${ }^{8}$, o Núcleo estadual da Luta Antimanicomial, denominado assim desde 1998, é responsável por organizar a comemoração de datas, realizar eventos nos mais diversos espaços da cidade, ocupar as ruas e os diferentes espaços de controle social e fazer incidências políticas.

No que se refere aos serviços de atenção substitutivos, as ações do Núcleo foram fundamentais para forçar a ampliação, com implementação de CAPS e demais serviços. Também incidiram no processo de desinstitucionalização das pessoas confinadas no maior Hospital psiquiátrico do estado (antigo Adauto Botelho). Nos anos 2000, vale destacar uma marcante incidência do Movimento no interior do estado, no município de Cachoeiro de Itapemirim (2012) para o fechamento da maior clínica psiquiátrica asilar privada e conveniada com o SUS no ES - a Clínica Santa Isabel. Mas recentemente os en-

\footnotetext{
${ }^{8}$ Não há uma publicação sobre essa trajetória da Luta Antimanicomial no ES disponível. O que encontramos são fragmentos em trabalhos acadêmicos diferentes. A profa aposentada Dra. Ana Heckert do Departamento de Psicologia da UFES disponibilizou um artigo iniciado (mas não publicado), no qual também buscou reunir os fragmentos dessa história e gentilmente cedeu essas informações. Grande parte das informações aqui foram obtidas durante a pandemia, pelo grupo Fênix/UFES em um projeto onde foram entrevistadas pessoas referências no campo da saúde mental e que participaram ativamente durante vários anos (familiares, gestores, profissionais, acadêmicos etc.).
} 
frentamentos se ampliam junto à gestão estadual quanto ao financiamento de comunidades terapêuticas para internar pessoas que consomem drogas; e na pauta sobre o atendimento ofertado a crianças e adolescentes considerado precário na rede estadual, entre tantas outras bandeiras de atuação.

O Núcleo também associou suas lutas a dois outros movimentos importantes no contexto capixaba - o Fórum Metropolitano sobre drogas ${ }^{9}$ e o Fórum Capixaba em Defesa da Saúde Pública ${ }^{10}$. Esses 3 movimentos têm trabalhado para defender as pautas referentes às Políticas de Saúde, sobre drogas e Saúde Mental no estado ${ }^{11}$. Juntos elaboraram uma Carta de Princípios - SUS tentando as Reformas Sanitária e Psiquiátrica. A partir desse documento, fizeram incidências junto a deputados, gestores estaduais e municipais, assim como fizeram manifestações, eventos e tiveram uma participação ativa para a criação da Frente Parlamentar em defesa da Reforma Psiquiátrica na Assembleia Legislativa do estado do ES. Participaram juntos de audiências públicas e eventos denunciando as violações de direitos das pessoas com transtorno mental e das que consomem drogas. Assumiram também assentos em espaços formais de controle social como conselhos estaduais e municipais (sobre drogas, saúde, pessoas com deficiência), além de diversas outras intervenções.

O que temos nessa trajetória de mais de 20 anos é a consolidação de um Núcleo Estadual da Luta Antimanicomial com a participação de usuários, familiares, profissionais e estudantes de um modo geral (sendo o segmento de familiares de mais difícil adesão, seguido do de usuários). É uma organização que não está criada por nenhum

\footnotetext{
${ }^{9}$ É um espaço coletivo e permanente de organização política e discussão sobre questões relacionadas ao uso de álcool e outras drogas, envolvendo organizações governamentais e não governamentais pessoas comprometidas com a temática, bem como usuários e familiares dos diversos serviços.

${ }^{10} \hat{E}$ um movimento social vinculado à Frente Nacional Contra a Privatização da Saúde, composto por trabalhadores/trabalhadoras, usuários/usuárias, entidades, movimentos sociais e estudantis, fóruns de saúde, centrais sindicais, sindicatos, partidos políticos e projetos universitários que, juntamente com os demais fóruns nacionais e locais, lutam para resistir e impedir que os interesses de grupos privados destruam o SUS.

${ }^{11}$ Todas informações apresentadas aqui sobre as ações empreendidas pela luta antimanicomial no ES na pandemia estão descritas a partir das próprias vivências das autoras do capítu lo, considerando a vinculação orgânica que possuem com os Movimentos citados. E também pelo acesso direto aos registros (como atas de reuniões e demais documentos) e na elaboração conjunta dos documentos produzidos por essa militância.
} 
ato normativo e não possui hierarquia organizacional. No entanto, isso não impede que seja ativo e legitimado no que se refere às demandas da saúde mental capixaba, consolidando como um espaço potente também para a luta antimanicomial brasileira (AMORIM, 2014).

Essa organização coletiva permanece desafiada à resistência e criação de propostas de superação das demandas (sejam as antigas e ainda permanentes, seja as novas evocadas pela pandemia). As problematizações apontadas no item anterior sobre as dinâmicas dos movimentos sociais e as problematizações necessárias a eles, nos levam a analisar de forma mais próxima a repercussão para a luta antimanicomial no ano em que se instala a pandemia por COVID-19. As lutas em nome das pessoas com transtornos mentais, acrescidas das lutas antiproibicionistas no campo das drogas nesse conjunto do movimento antimanicomial, estão também sacudidas por todos esses desafios.

No caso do ES, o movimento da luta conseguiu realizar algumas incidências políticas a partir de reuniões realizadas de forma virtuais entre os militantes desse movimento e também associando militantes dos dois outros movimentos, já mencionados. Foram feitas reuniões online com a vice-governadora do estado e gestores da Secretaria estadual de Saúde com o objetivo de denunciar as: dezenas de casos de não atendimento às demandas em saúde mental relatados por familiares e usuários da rede de atenção; cobrar medidas urgentes de organização da rede de atenção; requerer as devidas explicações porque em 5 meses de pandemia instalada no estado não foi publicada nenhuma normativa/orientação para a política estadual de saúde mental, além de não constar no Plano de contingência do governo nenhuma menção à área demonstrando completo descaso com essas demandas na pandemia; entregar um Documento elaborado pelos Movimentos (em maio de 2020) solicitando a implementação imediata de um Plano operacional de emergência em saúde mental a partir daquele momento; e a necessidade de recomposição do Grupo Condutor da Rede de Atenção Psicossocial (RAPS) estadual e a convocação imediata de reunião (o grupo estava desarticulado desde antes da pandemia e nitidamente percebe-se o desinteresse do Estado no fortalecimento desse espaço); entre outras pautas. 
Cabe dizer que toda essa articulação para acessar o gabinete do governo estadual foi feita pela Frente Parlamentar em defesa da Reforma, através da sua coordenação. Nesse contexto de completa ausência de ações pela Secretaria estadual de saúde (se compararmos inclusive, com o que foi possível realizar e conquistar em tempos anteriores em que a Política de Saúde Mental já teve uma prioridade estatal), os movimentos foram surpreendidos com a informação de que a Subsecretaria estadual de Políticas sobre drogas (que está desarticulada das ações da Política de Saúde mental de responsabilidade da Secretaria de Saúde, agindo sempre de modo paralelo nas ações e às vezes, assumindo pautas/demandas do campo da saúde de forma equivocada) estava realizando algumas ações de enfrentamento à pandemia como a internação de pessoas em situação de rua contaminadas pelo coronavírus nas comunidades terapêuticas credenciadas com o governo por meio de Edital público de financiamento $^{12}$. O que demonstra o rumo conservador e retrógrado da política sobre drogas estadual historicamente problemática quanto às violações de direitos.

\section{Vamos à luta: o Movimento em ação em tempo de pande- mia}

O Documento elaborado em suas 7 páginas, apresentou argumentos sobre a necessidade de se colocar em pauta as demandas da saúde mental em âmbito estadual (ainda que também não há medidas efetivas por parte do Governo federal); e também apresentou algumas Recomendações sobre a Política de Saúde Mental no tempo presente da pandemia e após ela, para que o Governo estadual implementasse em seus planos de contingência ações específicas para a saúde mental (incluindo as ações demandas pelo consumo de drogas). O Documento partiu das recomendações de órgãos e mecanismos nacionais (no caso Fundação Instituto Oswaldo Cruz - FIOCRUZ, o

\footnotetext{
${ }^{12}$ Essa Subsecretaria está vinculada à Secretaria estadual de Direitos Humanos. O relato mencionado foi feito em Reunião Ordinária do Conselho Estadual sobre drogas (COESAD) no dia 07 de julho de 2020, constando em Ata essa informação, assim como o repúdio do Núcleo da Luta Antimanicomial e demais conselheiros no campo da resistência em relação ao absurdo fato relatado.
} 
próprio Ministério da Saúde e o Conselho Nacional de Saúde) e internacionais como a Organização Mundial de Saúde (OMS) que no Plano de Ação Global renovado (2020-2030) ${ }^{13}$, acrescentou um objetivo específico sobre Saúde mental em emergências humanitárias. Entre as ações desse novo Plano de Ação, foi indicada que a saúde mental deve ser colocada nos comitês nacionais e locais de emergência. A Organização das Nações Unidas (ONU) lançou documento que apontava os impactos da COVID-19 na saúde mental das populações, recomendando que as políticas de enfrentamento pudessem prever e implantar serviços de qualidade e permanentes para seu enfrentamento, enfatizando a necessidade também no contexto pós pandemia de modo a reconstruir sistemas sustentáveis que considerem a saúde mental baseada na comunidade ${ }^{14}$.

Essas recomendações vêm, no caso do Brasil, em um contexto de empobrecimento dos serviços, com reduções e a escassez de pessoal como mencionado, que ratificam a saúde mental no final da lista de prioridades de saúde, como exemplo é o que vivenciamos no ES. Segundo a OMS (2020), a incerteza do momento, os riscos de contaminação, a necessidade de distanciamento social, o desemprego entre outros motivos, podem agravar ou causar problemas mentais e psicológicos no período da pandemia e após. Sem contar a situação dos profissionais que estão nas linhas de frente de atuação e também as questões relacionadas ao uso de álcool e outras substâncias psicoativas. Se considerarmos que o contexto de desafios está colocado desde março de 2020 (dia 11 de março a OMS anunciou a existência de uma pandemia pelo novo coronavírus; no Brasil foi em 20 de março ${ }^{15}$ e no ES desde 30 março $^{16}$ ) estados e municípios deveriam ter or-

\footnotetext{
${ }^{13}$ Disponível em <https://www.paho.org/bra >. Acesso em: 10 set. 2020.

14 Cabe abrir um parêntese para dizer que, ainda que haja a compreensão de que esses Organismos internacionais apresentem as suas pautas sob os ditames do capital e dos indicativos do Banco Mundial e Fundo Monetário Internacional, no quesito orientações na pandemia, ainda são as referências sanitárias de importantes a se considerar.

${ }^{15}$ No Brasil, foi declarada emergência em saúde pública em 04 de fevereiro (Portaria no 188/GM/MS), sendo que desde 10 de janeiro a situação já era analisada pela Vigilância Sanitária. Mediante isso, foi criado um Centro de Operações de Emergência (COE) em 22 de janeiro. Em 20 de março, foi publicada a Portaria № 454 que declarou em todo o território nacional, o estado de transmissão comunitária do coronavírus.

${ }^{16}$ No caso do ES, o Governo estadual decretou estado de emergência em 13 de março (Decreto $n=4593-R$ ) e estado de calamidade pública em 02 de abril (Decreto no 0446-S). Desde
} 
ganizado seus planos e contingência incluindo essas demandas.

Nessa conjuntura, o Núcleo da Luta, juntamente com os demais militantes, passaram a acompanhar todas as normativas publicadas pelo governo estadual e constatou-se que em nenhuma medida publicada mencionou-se ações específicas, seja para as populações já usuárias da RAPS/e rede socioassistencial, seja para a população que passou a demandar intervenções especializadas na saúde mental. Algumas Notas Técnicas ${ }^{17}$ abordaram o tema de uma forma muito abrangente. E nem os mapeamentos de riscos publicados sequer mencionaram os agravos em saúde mental como um problema a ser diagnosticado e enfrentado pelas políticas públicas existentes. Além disso, o movimento da luta comemorou o Dia 18 maio de forma alternativa e exclusiva nas redes sociais com a elaboração de vídeos envolvendo usuários, familiares e trabalhadores. Considerando as restrições de distanciamento nos serviços e a suspensão de algumas atividades, em alusão à data a Frente Parlamentar fez uma pequena fala em sessão online na Assembleia. O Núcleo também assinou Notas e Manifestos organizados em âmbito estadual denunciando e repudiando os retrocessos e ausências de ações na pandemia. Assim como denunciou nas mídias locais alguns desses retrocessos e ausências de respostas.

o dia 30 de março, o governo declarou o reconhecimento do estado de transmissão comunitária no ES. E em 19 de abril, publicou-se o Decreto n 4636-R que instituiu o mapeamento de risco para o estabelecimento de medidas qualificadas para o enfrentamento da emergência de saúde pública e posteriormente algumas Portarias que dispõem sobre esse mapeamento de risco; Além de outras normativas e o próprio Plano de Contingência. Informações disponíveis em <https://coronavirus.es.gov.br/plano-de-contingencia>.

17 1) Nota Técnica COVID-19 N 14/2020 SESA/SSAS/GROSS/NEAE-RCPD - Recomendações para prevenção e controle de infecções pelo novo coronavírus (COVID-19) para Atenção à Pessoa com Deficiência; 2) Nota Técnica COVID-19 no 10/2020 SESA/SSAS/GROSS/NEAE/ RCPD/FEDERAÇÃO DAS APAES DO ES que dispõe sobre Orientações Relativas ao Coronavírus para os Serviços que Compõem a Rede de Cuidados à Saúde da Pessoa com Deficiência e as Entidades Filantrópicas que Ofertam Atendimento em Saúde às Pessoas com Deficiência; 3) Nota Técnica COVID-19 № 17/2020 - SESA/SSAS/GROSS/NEAPRI EQUIDADE - Recomendações para prevenção e controle de infecções pelo novo coronavírus (COVID-19) para Organização da Rede Assistencial para Atenção às Pessoas em Situação de Vulnerabilidade; 4) Nota Técnica COVID-19 n 19/2020 SESA/SSAS/GROSS/NEAPRI sobre a Atenção Primária em saúde (APS) e os cuidados com seu território; 5) Nota Técnica COVID-19 N³0/2020 - SESA - Projeto "Cuidar de Quem Cuida" Ação Estratégica de Promoção e Prevenção à Saúde dos Servidores da SESA frente a pandemia da COVID-19. Essa é a Nota que chega mais próximo a uma ação concreta para os/as profissionais da saúde em geral. 
Sabemos que as restrições impostas pela pandemia vêm dificultando ações mais amplas e diretas nos espaços necessários pelo movimento da luta ${ }^{18}$. Ainda assim, cabe a autocrítica que deve ser feita pelo Movimento, na perspectiva apontada por Eduardo Vasconcelos (2020), chamando a atenção para uma tendência de pensar a política de saúde mental em si mesma, de forma isolada da conjuntura mais ampla e das demais políticas sociais. O "segurar a reforma psiquiátrica à unha" (VASCONCELOS, 2020, p. 8), como diz o autor, só levará os militantes a consequências preocupantes como esgotamento, há práticas burocráticas e defensivas ou ainda ao abandono da luta. Portanto, o que é importante frisar que qualquer ação empreendida pelos sujeitos coletivos no campo antimanicomial deve vir precedida de uma análise da conjuntura mundial e brasileira, reconhecendo o caráter global e multidimensional do projeto neoliberal em sua versão mais radical que gera uma crise civilizatória nos moldes de barbárie (VASCONCELOS, 2020). Se a militância insistir em ações pontuais (embora sejam necessárias), mas imersas nos mesmos discursos e práticas da essência do Movimento em mais de 40 anos de história de resistência no campo da saúde mental, avançaremos muito pouco ou nada. É urgente atualizá-los, sem negar todas as conquistas empreendidas e ainda em processo. Se hoje cabe aos coletivos processarem a autocrítica necessária para o avanço (LEAL, 2020), é preciso desenvolvermos "a capacidade de acompanhar e interpretar os 'sinais dos tempos' [...], considerando a conjuntura histórica para, então, compreender as contradições, prever os desafios e mirar nas brechas para a resistência" (VASCONCELOS, 2020, p. 22).

E partindo do pressuposto da completa relação entre a Luta Antimanicomial e as pautas do Serviço Social brasileiro, exploraremos a seguir esse campo à luz das deliberações do conjunto Conselho Federal de Serviço Social-Conselhos Regionais de Serviço Social (CFESSCRESS) sobre essa temática.

\footnotetext{
${ }^{18} \mathrm{E}$, de modo algum, a crítica aqui está voltada individualmente aos sujeitos envolvidos no movimento em meio aos desafios conjunturais.
} 


\section{A luta antimanicomial e o Serviço Social em tempos de pandemia}

Para as/os assistentes sociais no Brasil, o campo da saúde mental está intimamente relacionado ao projeto profissional nas perspectivas ética e política. Esse é marcado por um dilema que articula, de forma complexa, as conquistas no campo social e no campo psicossocial, com o desenvolvimento de processos de subjetivação que buscam a autonomia e a reinvenção da sociabilidade, trabalho, moradia, lazer, educação etc. Porém, nos países latino-americanos, as reivindicações emancipatórias no campo da subjetividade se combinam necessariamente com lutas por garantias mínimas de cidadania social que nunca foram conquistadas pela população (VASCONCELOS, 2002).

Denadai e Garcia (2016) já se perguntavam e investigaram como esse debate das políticas de saúde mental e sobre drogas se inscrevem no interior da produção intelectual do Serviço Social brasileiro. Em análise dessa produção, por exemplo, apontaram a necessidade de incremento da fundamentação dos debates na área a partir de uma orientação teórico crítica. Essa demarcação para o Serviço Social traz consigo alguns desafios imperativos como o de construir coletivamente estratégias para que os fundamentos da profissão sejam apreendidos por toda a categoria profissional e, sobretudo, que se garanta a interlocução com os movimentos sociais de luta. De modo que essa orientação crítica particular da categoria, possa reverberar e contribuir para as reflexões junto às classes trabalhadoras nas suas lutas organizadas ${ }^{19}$.

A despeito de ser um espaço de inserção dos assistentes sociais desde as origens da profissão, a saúde mental e os assuntos relacionados (como as drogas, por exemplo) é um assunto tratado nos Relatórios de Gestão do CFESS somente dos anos 1990 para cá. Em 1998 o tema aparece no 9o Congresso Brasileiro de Assistentes Sociais na Plenária Descriminalização das Drogas. Desde então, de forma

\footnotetext{
${ }^{19}$ Mediante essa demanda, um grupo de pesquisadores de diferentes Universidades (UFES, UFRJ, UFJF, UEL, IFCE, entre outras) vem organizando uma Rede de Pesquisa sobre Questão Social, Questão das drogas e Saúde mental, de modo a intercambiar as discussões e organizar as produções no âmbito da categoria.
} 
mais incisiva e com maior frequência a partir dos anos 2000 que notamos a participação da categoria de forma mais organizada em diferentes espaços com essas pautas, como: Conferências Nacionais e locais; inserção em conselhos gestores relacionados a essas políticas; deliberações nos Encontros Nacionais da categoria a partir de uma agenda de trabalho; participação em Comissões intersetoriais nacionais vinculadas ao Ministério da Saúde e demais Ministérios afins; organização de Seminários/eventos para a própria categoria; garantia do debate nos Congressos Brasileiros de Assistentes Sociais, entre outras ações. Dessa forma, o Serviço Social brasileiro tem dado uma contribuição principalmente política ao tema saúde mental e drogas a partir da análise teórico crítica que possibilita a apreensão e a revelação das múltiplas expressões da questão social presentes. Através da publicação periódica - CFESS Manifesta ${ }^{20}$, que manifesta politicamente os posicionamentos a respeito dos diversos temas relacionados à categoria, sobre o tema saúde mental e drogas foram publicadas algumas edições com essa problematização.

Outros exemplos importantes são as deliberações da categoria por meio dos Encontros Nacionais e Regionais. 0 41을 Encontro Nacional realizado em Palmas/TO (2012) deliberou no Eixo Ética e Direitos Humanos ${ }^{21}$ a necessidade da categoria profissional se posicionar politicamente contra as internações compulsórias, reforçando o dever profissional na luta pelos direitos humanos e a aliança com os movimentos sociais de resistência. $E$, no 42 을 Encontro realizado em Recife (2013), aprovou-se o documento ${ }^{22}$ intitulado Internação compulsória e a violação de direitos humanos! O texto explicitou que a categoria reitera publicamente a luta em defesa dos princípios da RP, de políticas públicas sobre drogas baseadas nos direitos humanos, respeito aos princípios do SUS e às diretrizes da IV Conferência Nacional de Saúde Mental -Intersetorial e da 14ạ Conferência Nacional de Saúde. E no mesmo Encontro, os/as delegados/as presentes defini-

\footnotetext{
20 Publicação periódica na qual o Conjunto CFESS/CRESS afirma os principais posicionamentos ético-políticos da categoria. Disponíveis em <www.cfess.org.br>.

${ }^{21}$ Disponível em <http://www.cfess.org.br/js/library/pdfjs/web/viewer.html?pdf=/arquivos/ relatorio-en-2012-versao-final-outubro.pdf $>$.

22 Disponível em <http://www.cfess.org.br/js/library/pdfjs/web/viewer.html?pdf=/ arquivos/relatorio-nacional-2013-.pdf>.
} 
ram democraticamente sobre o posicionamento a favor da descriminalização do consumo de drogas.

Quanto ao debate teórico específico, historicamente, a profissão não assumiu com o devido rigor, embora o tema estivesse presente no cotidiano dos profissionais, principalmente, nos atuantes na Política de Saúde. Questões de fundo relacionadas a um debate mais amplo que possibilitasse sair do lugar comum (ser humano $X$ consumo de drogas) não foi algo assumido pelo Serviço Social brasileiro ao longo de sua consolidação enquanto profissão. Entretanto, a profissão vem contribuindo com o debate político sobre os princípios da RP e a atuação profissional dos assistentes sociais, principalmente, devido a inserção de muitos assistentes sociais nos movimentos da luta antimanicomial pelo país afora. No ES é visível identificar a presença e a contribuição importante das assistentes sociais nos espaços de militância antimanicomiais. E em muitas das ações, contam com o apoio do CRESS 17a Região/ES.

Em termos das iniciativas no momento presente da pandemia, além das normativas de orientação para a atuação das assistentes sociais na saúde (e consequentemente na saúde mental) o CFESS publicou a Série CFESS Entrevista ${ }^{23}$. Nessa série, destacamos: a) debate sobre a problemática do trabalho com população de rua (CFESS entrevista mais uma assistente social, para debater a atuação profissional na pandemia do Covid-19), destacando aspectos do trabalho desenvolvido pelo Consultório na Rua, por exemplo; e b) no debate sobre o trabalho das assistentes sociais na área da saúde, a saúde mental aparece na importância de estratégias voltadas para a saúde mental e o nosso autocuidado enquanto trabalhadores/as da saúde. O CRESS 17ạ Região/ES ${ }^{24}$ também vem apresentando intervenções junto à categoria e reforçando em cada documento de orientação que reconhecemos a mobilização de movimentos sociais que estão se posicionando e construindo alternativas para enfrentar a atual crise na perspectiva de ampliação dos direitos sociais. E que cabe aos assistentes sociais somar nessas lutas. Essa luta é urgente. O fechamen-

${ }^{23}$ Disponível em: <http://www.cfess.org.br/visualizar/menu/local/serie-cfess-entrevista>. Acesso em: 10 set. 2020.

${ }^{24}$ Disponível em: <http://www.cress-es.org.br/comunicados-do-cress-es-sobre-a-covid-19/>. Acesso em: 10 set. 2020. 
to de alguns serviços de saúde mental, deixou em descoberto uma população demandante por cuidados em saúde mental, problemática registrada em 18 países na região das Américas (OPAS, 2020).

A partir desse cenário apresentado pela e (para) profissão no Brasil, o Serviço Social precisa, então, fundamentar e amadurecer suas posições ético-políticas no interior do debate contemporâneo sobre as temáticas, considerando o desafio de se pensar, por exemplo, a inserção de assistentes sociais nos diferentes campos da Saúde Mental, problematizando alguns espaços de trabalho, como as comunidades terapêuticas religiosas ${ }^{25}$. No que se refere aos desafios para a militância da categoria em tempos de pandemia, estão na mesma direção que o conjunto da classe trabalhadora. Sendo necessário reforçar que as lutas políticas não se dão apenas no âmbito da sociedade civil, mas na totalidade da estrutura social e da formação social constituindo o bloco histórico (BRAVO; CORREIA, 2012).

\section{Considerações finais}

O que impera a partir dessa caótica conjuntura política e econômica é a necessidade urgente de transformar colocando as necessidades humanas no centro das prioridades. Os interesses dos que cotidianamente sofrem com essas opressões vão de encontro aos interesses dos grandes monopólios capitalistas. E no caso dos considerados "loucos" e "viciados/dependentes", isso ainda se torna mais marginal.

Para mantermos a grande aposta histórica de uma desinstitucionalização na saúde mental "orientada por valores radicalmente democráticos, requer revisitar a processualidade histórica que a conforma o tipo de democracia burguesa e identificar pistas para a luta política" (CAVALCANTE, 2020, p. 41). Nesse ínterim, o Serviço Social brasileiro se mantém convocado a aliar a sua concepção teórica e ética à militância política, sempre como um processo cumulativo de contribuição com a classe que vive do trabalho.

\footnotetext{
${ }^{25}$ Esse debate pode ser aprofundado no artigo LEAL, F. X.; GARCIA, M. L. T. Gastos com inter nações compulsórias por consumo de drogas no estado do Espírito Santo, 2020 (no prelo).
} 
Ratificamos que a tragédia social vivenciada pela pandemia que inicia em 2020 (mas não terminará aqui) não é causada pelo coronavírus, ainda que seja amplificada exponencialmente pela doença causada por ele. Por conta disso, as demandas que teremos pela frente são ainda mais desafiadoras. $E$, assim, precisamos retomar o velho Gramsci com o seu clássico otimismo da vontade ao analisar esta barbárie. Uma crise brutal na era da mundialização do capital traz também, em seu interior, a possibilidade da mundialização das rebeliões e das lutas sociais (ANTUNES, 2020). E no otimismo gramsciano seguimos entoando o cântico do Bloco Capixaba Que Loucura "O nosso som é o som da liberdade. A nossa voz ecoa nessa cidade".

\section{Referências}

ALMEIDA, L. M. C. Política de saúde mental no Brasil: o que está em jogo nas mudanças em curso. Cadernos de Saúde Pública. Rio de Janeiro, v. 35, n. 11, e00129519, 2019.

ALMEIDA FILHO, A. J. de. et al. Trajetória histórica da reforma psiquiátrica em Portugal e no Brasil. Revista de Enfermagem Referência, Coimbra, 2015, v. 4, n. 4. p. 117-125.

AMARANTE, P. Loucos pela vida: a trajetória da reforma psiquiátrica no Brasil. Rio de Janeiro: Fiocruz; 1995.

Saúde mental e atenção psicossocial. Rio de Janeiro: Fiocruz. 2007.

AMARANTE, P.; NUNES, M. de O. A reforma psiquiátrica no SUS e a luta por uma sociedade sem manicômios. Ciência \& Saúde Coletiva. Rio de Janeiro: ABRASCO, v. 23, n. 6, p. 2067-2074, jun. 2018.

AMORIM, R. G. As tessituras cotidianas que compõem as práticas de cuidado nas relações entre trabalhadores da saúde mental e usuários. 2014. Dissertação (Mestrado em Psicologia Institucional). Universidade Federal do Espírito Santo, Vitória, 2014.

ANTUNES. R. O Vilipêndio do coronavírus e o imperativo de reinventar o mundo. In: TOSTES, A.; FILHO MELO, H. (Org.). Quarentena: re- 
flexões sobre a pandemia e depois. 1.ed. Bauru: Canal 6, Projeto Editorial Praxis, 2020..

BARROCO, M. L. S. Barbárie e neoconservadorismo: os desafios do projeto ético-político. Serviço Social \& Sociedade, São Paulo, p. 205218, jun., 2011. Disponível em <http://www.scielo.br/scielo.php? script=sci_arttext\&pid=S010166282011000200002\&Ing=en\&nrm=iso>. Acesso em: 07 set. 2020.

BEHRING, E. R. Brasil em contrarreforma: desestruturação do Estado e perda de direitos. São Paulo: Cortez, 2003.

BRAVO, M. I. S, CORREIA, M. V. C. Desafios do controle social na atualidade. Serviço Social \& Sociedade, São Paulo, n. 109, p. 126-150, jan./mar. 2012.

CAVALCANTE, R. O social para a saúde mental sob a contrarreforma neoliberal. Argumentum, Vitória, v. 12, n. 2, p. 36-43, mai./ago., 2020. Disponível em: <https://doi.org/10.18315/argumentum.v12i2.30483>. Acesso em: 12 set. 2020.

CORREA, M. V. C. Controle social na saúde. In: MOTA, A. E. et. al. (Org.). Serviço Social e saúde: formação e trabalho profissional. São Paulo; Brasília: Cortez Editora; OPAS; OMS; MS, 2007.

DENADAI, M. C. V. B. O legislativo federal e os projetos de lei sobre drogas no Brasil: uma guerra entre velhos discursos ou novas alternativas? 2015. Tese (Doutorado em Serviço Social) - Programa de Pós-Graduação em Serviço Social. Escola de Serviço Social. Universidade Federal do Rio de Janeiro, Rio de Janeiro, 2015.

DENADAI, M. C. V. V.; GARCIA, M. L. T. O Serviço Social e a temática droga. Sociedade em Debate, Pelotas, v. 22. p. 261-289, 2016.

DUARTE, S. L. A luta antimanicomial e a política de saúde mental no Brasil. Dissertação (Mestrado em Política Social) - Programa de PósGraduação em Política Social. Universidade Federal do Espírito Santo, Vitória, 2014.

GRANEMANN, S. Necessidades da acumulação capitalista. Revista Inscrita, Ano VI, n. IX, p. 29-32, 2004. 
HARVEY, D. O neoliberalismo: história e implicações. 2. ed. São Paulo: Loyola, 2008.

LEAL, F. X. Conselhos municipais antidrogas: entre o sonho e a realidade. Dissertação (Mestrado em Política Social) - Programa de PósGraduação em Política Social. Universidade Federal do Espírito Santo, Vitória, 2006.

. Movimento antiproibicionista no Brasil: discursos de resistência. Tese (Doutorado em Política Social) - Programa de Pós-Graduação em Política Social. Universidade Federal do Espírito Santo, Vitória, 2017.

As estratégias de resistência para a luta antimanicomial. Argumentum, Vitória, v. 12, n. 2, p. 27-35, mai./ago., 2020. Disponível em <https://doi.org/10.18315/argumentum.v12i2.30483>. Acesso em: 12 set. 2020.

LIMA, R. C. O avanço da contrarreforma psiquiátrica no Brasil. Physis - Revista de Saúde Coletiva, v. 29, n. 1, p. 1-5, 2019. Disponível em: < https://www.scielo.br/scielo.php?script=sci_arttext\&pid=S0103$73312019000100100 \& \operatorname{lng}=e n \& n r m=i s o \& t \operatorname{lng}=p t>$. Acesso em: 11 mar. 2020.

LOBOSQUE, A. M. Experiências da loucura. Rio de Janeiro: Garamond, 2001.

LÖWY, M. Gripezinha e o neofascista Bolsonaro diante da epidemia. In: TOSTES, A.; FILHO MELO, H. Org.). Quarentena: reflexões sobre a pandemia e depois. 1.ed. Bauru: Canal 6, Projeto Editorial Práxis, 2020.

LÜCHMANN, L. H. H; RODRIGUES, J. O movimento antimanicomial no Brasil. Ciência \& Saúde Coletiva, v.12, n. 2, p. 399-407, 2007.

MERHY, E.; AMARAL, H. A reforma psiquiátrica no cotidiano II. São Paulo: HUCITEC, 2007.

NETTO, J. P. Capitalismo e reificação. São Paulo: Livraria Editora Ciências Humanas, 1981.

. Capitalismo e barbárie contemporânea. Argumentum, Vitória, v. 4, n. 1, p. 202-222, jan./jun., 2012. 
; BRAZ, M. Economia política: uma introdução crítica. São Paulo: Cortez, 2007.

NETTO, L. E. O conservadorismo clássico: elementos de caracterização e crítica. São Paulo: Cortez, 2011.

ORGANIZAÇÃO PANAMERICANA DE SAÚDE - OPAS. COVID-19 has impacted the operation of health services for noncommunicable diseases in the Americas. Junho, 2020. Disponível em: <https://www.paho.org/en/news/17-6-2020-covid-19-has-impacted-operation-healthservices-noncommunicable-diseases-americas>. Acesso em: 15 ago. 2020.

PAIM, J. S. Bases conceituais da reforma sanitária brasileira. In: FLEURY, S. (Org.). Saúde e democracia: a luta do CEBES. São Paulo: Lemos Editorial. 1997.

PINHEIRO, P. W. M. Serviço Social, neoconservadorismo religioso e o desafio para a formação profissional. Temporalis, Brasília (DF), ano 15, n. 29, p. 195-220, jan./jun. 2015.

PITTA, A. Um balanço da reforma psiquiátrica brasileira: instituições, atores e políticas. Ciência \& Saúde Coletiva, Rio de Janeiro, v. 16, n. 12, p. 4579-4589, 2011. Disponível em: <https://www.scielo.br/pdf/ csc/v16n12/02.pdf>. Acesso em: 10 set. 2020.

RAICHELIS, R. Esfera pública e conselhos de assistência social: caminhos de construção democrática. 3a ed. São Paulo: Cortez, 2005.

SIMIONATTO, I. O social e o político no pensamento de Gramsci. In: AGGIO, A. (Org.). Gramsci, a vitalidade de um pensamento. São Paulo: Fundação Editora UNESP, 1998.

SOALHEIRO, N. I. Da experiência subjetiva a prática política: a visão do usuário sobre si, sua condição, seus direitos. Tese (Doutorado em Saúde Pública) - Escola Nacional de Saúde Pública, Fundação Instituto Oswaldo Cruz. Rio de Janeiro, 2003.

VASCONCELOS, E. M. et al. Saúde mental e Serviço Social - o desafio da subjetividade e da interdisciplinaridade. São Paulo: Cortez, 2002. 
. Cenário econômico, social e psicossocial no Brasil recente, e a crescente difusão do crack: balanço e perspectivas de ação. $\mathbf{O}$ Social em Questão. Rio de Janeiro, ano 15, n. 28, p. 149-186, 2012.

. Reforma psiquiátrica, tempos sombrios e resistência: diálogos com o marxismo e o Serviço Social. São Paulo: Papel Social, 2016. . A gravidade do neoliberalismo radical pós 2008 e nossas estratégias de resistência. Argumentum, Vitória, v. 12, n. 2, p. 8-26, mai./ago., 2020. Disponível em <https://doi.org/10.18315/argumentum.v12i2.30483>. Acesso em: 12 set. 2020. 